\title{
Evolução das lesões histológicas e ultra-estruturais no fígado de ovinos e bovinos experimentalmente intoxicados por Myoporum laetum $^{1}$
}

\author{
Josiane Bonel-Raposo ${ }^{2 *}$, David Driemeier ${ }^{3}$, Severo Sales Barros ${ }^{4}$ \\ e Cristina Gevehr-Fernandes ${ }^{5}$
}

\begin{abstract}
Bonel-Raposo J., Driemeier D., Barros S.S. \& Gevehr-Fernandes C. 2003. [Histological and ultrastructural evolution of liver lesions in experimental Myoporum laetum poisoning of sheep and cattle.] Evolução das lesões histológicas e ultra-estruturais no fígado de ovinos e bovinos experimentalmente intoxicados por Myoporum laetum. Pesquisa Veterinária Brasileira 23(4):149-155. Depto Patologia Animal, Faculdade de Veterinária, UFPel, Pelotas, RS 96010900, Brazil. E-mail: bonel-raposo@brturbo.com

Green leaves of Myoporum laetum were collected during spring and summer, and administered to five sheep and six steers at dosages of 20 and $30 \mathrm{~g} / \mathrm{kg}$. Liver biopsies were taken before (Controls) and 1, 3 and 7 days after dosage. In sheep, the clinical signs were depression, rumen hypomotility, dried feces, tenesmus, teeth grinding, dyspnea and typical lesions of photosensitization. In cattle, the clinical picture was much less pronounced. The main histological findings in sheep were vacuolization of hepatocytes, portal fibrosis, bile duct proliferation and necrosis of periportal hepatocytes; the ultrastructural examination revealed hyperplasia of the smooth endoplasmic reticulum, hepatocellular hydropic degeneration, presence of crystals and several other degenerative changes. In cattle both, the histological and the ultrastructural findings, were less evident.
\end{abstract}

INDEX TERMS: Poisonous plants, plant poisoning, Myoporum laetum, sheep, cattle.

RESUMO.- Amostras de Myoporum laetum foram colhidas durante a primavera e verão e administradas a cinco ovinos e seis bovinos em doses únicas de 20 e $30 \mathrm{~g} / \mathrm{kg}$. Biópsias hepáticas foram colhidas antes (controles) e 1, 3 e 7 dias após a dosagem da planta. Estas biópsias foram analisadas histológica e ultraestruturalmente. Os sinais clínicos, em ovinos, caracterizaramse, especialmente, por depressão, diminuição dos movimen-

${ }^{1}$ Recebido em 28 de março de 2003

Aceito para publicação em 9 de maio de 2003.

${ }^{2}$ Acadêmica do Curso de Pós-Graduação em Ciências Veterinárias, Universidade Federal do Rio Grande do Sul (UFRGS), Área de Patologia. "Endereço do Autor para correspondência: Departamento de Patologia Animal, Faculdade de Veterinária, Universidade Federal de Pelotas (UFPel), Pelotas, RS 96010-900, Brasil. E-mail: bonel-raposo@brturbo.com

${ }^{3}$ Departamento de Patologia Clínica Veterinária, UFRGS, Cx. Postal 15094, Porto Alegre , RS, 91540-000.

${ }^{4}$ Pesquisador Visitante da UFRGS e Bolsista da Fundação de Amparo à Pesquisa do Estado do Rio Grande do Sul (FAPERGS).

${ }^{5}$ Departamento de Patologia Animal, Faculdade de Veterinária, UFPel, Pelotas, RS. tos ruminais, fezes ressequidas, tenesmo, ranger de dentes, dispnéia e lesões típicas de fotossensibilização. Em bovinos, o quadro clínico foi discreto. Os principais achados histológicos, em ovinos, incluíram vacuolização de hepatócitos, fibrose portal, proliferação de ductos biliares e necrose de hepatócitos periportais. Os estudos ultra-estruturais, em ovinos, revelaram hiperplasia do retículo endoplasmático liso, tumefação de hepatócitos, degranulação e vesiculação do retículo endoplasmático rugoso, presença de cristais aciculares, retenção biliar, tumefação de mitocôndrias e várias outras alterações degenerativas. Em bovinos, tanto os achados histológicos, quanto os ultra-estruturais foram menos evidentes.

TERMOS DE INDEXAÇÃO: Plantas tóxicas, intoxicação por plantas, Myoporum laetum, ovinos, bovinos.

\section{INTRODUÇÃO}

Intoxicação por Myoporum sp tem sido descrita em diversos países (Allen et al. 1978, Seawright et al. 1978, Jerret \& Chinnock 1983, Odriozola et al. 1987), afetando bovinos, ovinos, eqüinos e suínos. No Uruguai, existem históricos clíni- 
cos da doença e, na região Sul do Rio Grande do Sul, são mencionados surtos de fotossensibilização em ovinos, associados ao consumo de Myoporum sp (Méndez et al. 1993).

Os compostos tóxicos desta planta são óleos essenciais furanosesquiterpenóides (FST), dos quais o mais conhecido é o ngaione. Os FST concentram-se principalmente nas folhas e nos frutos (Seawright et al. 1978). As diversas espécies e variedades de Myoporum sp possuem concentrações variadas de substâncias tóxicas e não-tóxicas. Portanto, ocasionalmente, pode haver consumo destas plantas, sem que ocorra doença. Podem ocorrer variações na toxicidade de plantas em uma mesma região (Allen \& Seawright 1973).

A ingestão pode ocorrer em diferentes circunstâncias tais como: após a queda de galhos e árvores por ventanias ou depois de podas; por consumo direto de folhas das árvores que estão ao alcance dos animais; quando, no inverno, há pouca disponibilidade de forragem; durante tempestades prolongadas quando animais procuram abrigo; ou ainda pode ocorrer em animais que foram recentemente transportados (Hurst 1942, Jerret \& Chinnock 1983, Odriozola et al. 1987, Méndez et al. 1993).

As lesões microscópicas observadas por Raposo et al. (1998a) de todos os ovinos caracterizaram-se por necrose hepática periportal. Lesões similares foram, também descritas por Allen \& Seawright (1973). As principais lesões nos bovinos localizam-se no fígado e caracterizam-se por necrose hemorrágica periportal (Jerrett \& Chinnock 1983); necrose difusa ou mediozonal (Odriozola et al. 1987), com proliferação de ductos biliares (Jerrett \& Chinnock 1983, Odriozola et al. 1987). No entanto, em intoxicações experimentais observaram-se preferentemente necrose hemorrágica centrolobular (Allen et al. 1978). As lesões histológicas descritas por Raposo et al. (1998b), em bovinos caracterizaram-se principalmente por necrose hepática centrolobular e, em alguns casos, estendendo-se até a área mediozonal.

As alterações ultra-estruturais observadas em camundongos experimentalmente intoxicados por via gástrica com ngaione de Myoporum deserti incluíram dilatação do retículo endoplasmático rugoso dos hepatócitos e perda das células de Kupffer da região mediozonal e necrose dos hepatócitos, verificadas respectivamente 1, 3 e 6 horas após a dosagem com o óleo. Uma área confluente de necrose coagulativa mediozonal estava presente 12 horas pós-ingestão e foi seguida por atividade fagocitária dos macrófagos. No período de 8 a 9 dias houve uma reparação quase completa das áreas mediozonais danificadas. Danos severos das células de Kupffer, durante os estágios iniciais, e uma rápida proliferação do retículo endoplasmático, em alguns hepatócitos danificados, foram características da lesão (Seawright \& O’Donahoo 1973).

A severidade e o padrão das lesões hepáticas dependem da interação de vários fatores como dieta, estado nutricional, administração concorrente de drogas, quantidade de planta ingerida e atividade enzimática (Allen et al. 1978, Seawright et al. 1978, Kelly 1993). O jejum pode induzir o catabolismo das proteínas, causando uma diminuição na concentração das enzimas na região centrolobular e, conseqüentemente, desintoxicação incompleta e acúmulo de metabólitos tóxi- cos, havendo, portanto a possibilidade de lesão nos hepatócitos locais (Kelly 1993). O tipo e a localização da lesão podem ser influenciados por vários fatores como a espécie da planta, o componente de óleo essencial, a atividade das enzimas microssomais hepáticas, a espécie e o sexo dos animais envolvidos (Ford \& Rivera 1978).

O objetivo deste trabalho é estudar a evolução das alterações histológicas e ultra-estruturais nos fígados de ovinos e bovinos intoxicados experimentalmente por Myoporum laetum.

\section{MATERIAL E MÉTODOS}

Cinco ovinos Corriedale e seis bovinos mestiços foram pesados, mantidos em jejum durante 24 horas e, utilizados neste experimento.

As amostras de Myoporum laetum foram colhidas na primavera de 2000 (outubro) e verão de 2001 (janeiro), mantidas sob refrigeração por 12 horas e administradas aos animais conforme esquema de dosagens apresentado no Quadro 1 . Todos animais experimentais foram clinicamente examinados 24 horas antes e, diariamente, após a ingestão da planta.

As amostras do fígado foram coletadas através de biópsias pelo

Quadro 1. Dosagens utilizadas na intoxicação experimental por Myoporum laetum em ovinos e bovinos

\begin{tabular}{lcccc}
\hline & \multicolumn{2}{c}{ Ovinos } & \multicolumn{2}{c}{ Bovinos } \\
\hline Dose única $(\mathrm{g} / \mathrm{kg})$ & 20 & 30 & 20 & 30 \\
Primavera de 2000 & 2 & - & - & - \\
Verão de 2001 & 1 & 2 & 3 & 3 \\
Total & 3 & 2 & 3 & 3
\end{tabular}

método de punção transtorácica usando-se agulha de Menghini (Braga et al. 1985). Cada amostra foi subdividida em duas porções, uma fixada em formol a $10 \%$, embebida em parafina, cortada e corada por hematoxilina-eosina (HE), von Kossa e ácido periódico de Schiff (PAS) para avaliação histológica e a outra foi subdividida em fragmentos fixados por imersão em glutaraldeído $2 \%$ e paraformaldeído $2 \%$ com tampão de cacodilato de sódio $(\mathrm{pH} 7,4)$ a ser utilizada para avaliação ultra-estrutural. Os fragmentos foram lavados em solução tampão com sacarose, pós-fixados em solução de tetróxido de ósmio, desidratados em concentrações crescentes de etanol e incluídos em Epon. Os cortes semifinos foram corados com azul de metileno e áreas selecionadas foram cortadas com navalha de diamante, contrastadas com acetato de uranila e citrato de chumbo e observadas em microscópio eletrônico de transmissão. As biópsias foram realizadas antes da administração da planta, no $1^{\circ}, 3^{\circ}$ e e $7^{\circ}$ dias após a administração. A primeira biópsia foi tomada como controle.

\section{RESULTADOS}

\section{Ovinos}

Sinais clínicos. Embora em diferentes níveis de severidade, todos os ovinos que receberam a planta, independentemente da dosagem, apresentaram depressão, ausência ou diminuição dos movimentos ruminais, fezes ressequidas com muco e sangue, mucosas vermelhas, tenesmo, ranger de dentes, dispnéia e lesões de fotossensibilização que se caracterizaram, inicialmente, por corrimento seroso ocular e nasal, edema nas orelhas e face, prurido, vermelhidão e, posterior- 


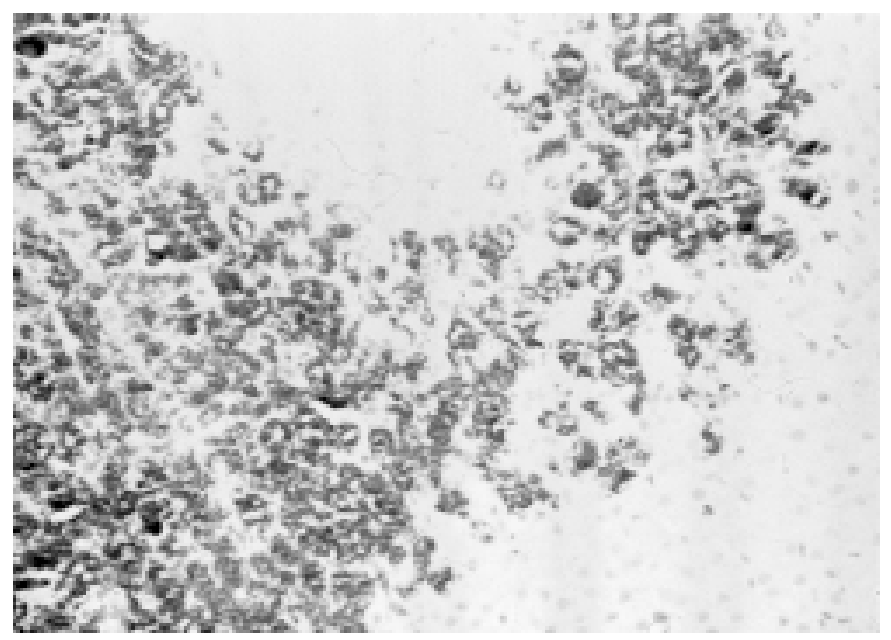

Fig. 1. Intoxicação por Myoporum laetum. Fígado. Ovino. Fino granulado von Kossa positivo, obj. 20.

mente, formação de crostas e perda de pêlos ao redor dos olhos e focinho.

Achados histológicos. As biópsias obtidas dos dois ovinos dosados em outubro com $20 \mathrm{~g} / \mathrm{kg}$ da planta apresentaram picnose e acidofilia do citoplasma de alguns hepatócitos, especialmente de localização periportal, mas também de alguns da região mediozonal, na verificação feita às 24 horas $e$ aos 3 e 7 dias após ingestão da planta. As lesões degenerativas evoluíram para necrose com desorganização da arquitetura lobular, hemorragia e discreta basofilia dos hepatócitos na região periportais na coloração de $\mathrm{HE}$, os quais mostravam um fino granulado von Kossa positivo (Fig. 1).

Nas biópsias do ovino que recebeu $20 \mathrm{~g} / \mathrm{kg}$ da planta em janeiro, observaram-se, a partir de 24 horas, vacuolização dos hepatócitos da região centrolobular e acúmulo de neutrófilos no interior de sinusóides. No $3^{\circ}$ dia após a dosagem, ainda eram observadas degeneração centrolobular e discreta necrose de alguns hepatócitos na área periportal com eritrócitos extravasados. Moderada fibrose portal e discreta proliferação ductal foram também observadas. No $7^{\circ}$ dia, observaram-se vacuolização moderada dos hepatócitos periportais e fibrose portal.

Dos dois ovinos que ingeriram $30 \mathrm{~g} / \mathrm{kg}$ em janeiro, um apresentou sinais clínicos similares aos ovinos intoxicados com $20 \mathrm{mg} / \mathrm{kg}$ e o outro mostrou sinais muito discretos. Nas biópsias do ovino que apresentou sinais mais evidentes, a partir de 24 horas após a administração da planta, foi verificada vacuolização dos hepatócitos centrolobulares e mediozonais. No $3^{\circ}$ dia, foram observadas necrose dos hepatócitos periportais e hemorragia, vacuolização dos hepatócitos centrolobulares e mediozonais, além de discreta proliferação de ductos biliares. No $7^{\circ}$ dia foram observadas áreas de necrose periportal com acúmulos de polimorfo-nucleares nos sinusóides, fibrose e proliferação ductal. Poucos hepatócitos apresentaram um fino granulado basófilo von Kossa positivo, e na coloração de HE não foi observada discreta basofilia dos hepatócitos. O outro ovino dosado com
$30 \mathrm{~g} / \mathrm{kg}$ apresentou vacuolização difusa dos hepatócitos nas primeiras 24 horas, permanecendo assim durante os 4 e 8 dias. As biópsias-controles, ou seja, aquelas tomadas antes do início do experimento não exibiram alterações microscópicas.

Achados ultra-estruturais. Nos ovinos que receberam 20g/ $\mathrm{kg}$ em outubro, observou-se nas primeiras 24 horas, hiperplasia do retículo endoplasmático liso (REL) que se acentuou no $3^{\circ}$ dia após ingestão da planta (Fig. 2). Foram encontradas algumas imagens negativas de cristais geralmente em forma de crescente, medindo de 3 a $6 \mathrm{~mm}$. No $7^{\circ}$ dia foram observados numerosos hepatócitos degenerados caracterizados por tumefação celular, dilatação, degranulação e vesiculação do retículo endoplasmático rugoso (RER), dilatação das mitocôndrias e núcleos com contornos irregulares e cromatina condensada. Em

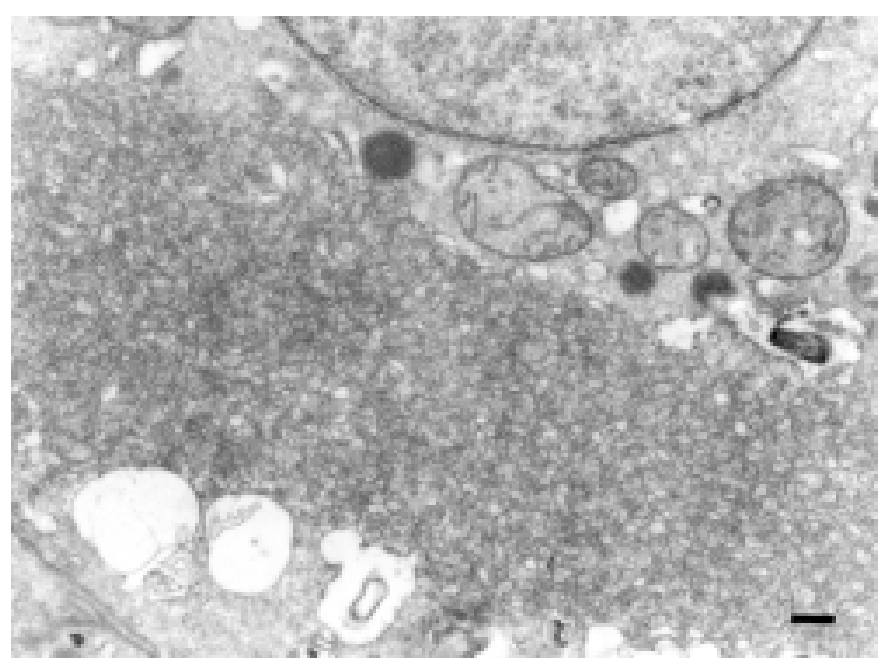

Fig. 2. Micrografia eletrônica. Fígado. Ovino. Hepatócito exibindo acentuada hiperplasia do retículo endoplasmático liso. Barra $=0,5 \mu \mathrm{m}$

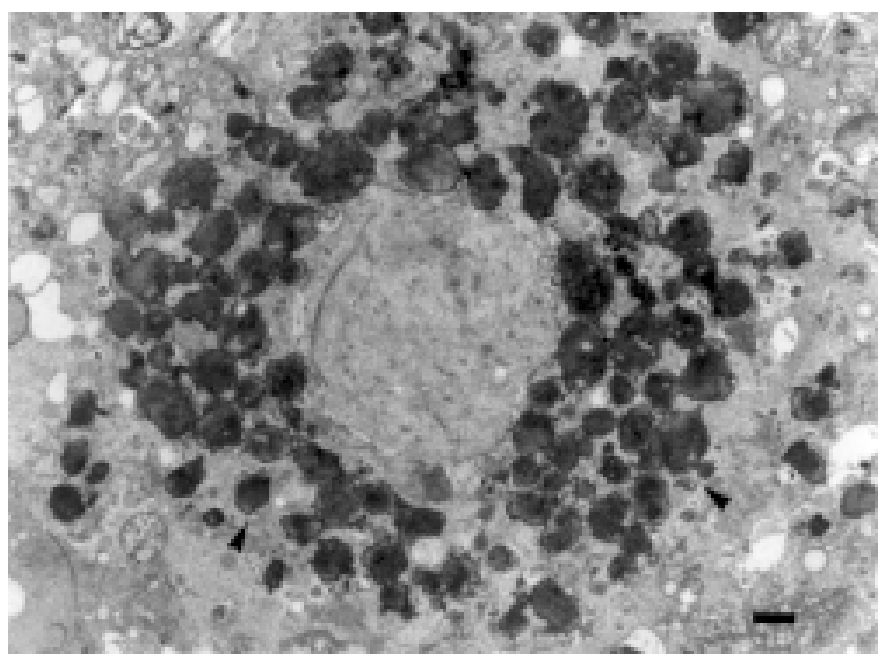

Fig. 3. Micrografia eletrônica. Fígado. Ovino. Hepatócito degenerado mostrando numerosas formações eletrodensas delimitadas por membrana (cabeça de seta). Barra $=1 \mu \mathrm{m}$ 
Quadro 2. Descrição das alterações histológicas e ultra-estruturais em fígados de ovinos experimentalmente dosados com Myoporum laetum

\begin{tabular}{|c|c|c|c|c|}
\hline \multicolumn{3}{|c|}{ Dosagem } & \multirow[t]{2}{*}{ Microscopia Óptica } & \multirow[t]{2}{*}{ Microscopia Eletrônica } \\
\hline Época & $\begin{array}{l}\text { Dose } \\
(\mathrm{g} / \mathrm{kg})\end{array}$ & $\begin{array}{c}\text { Dias após } \\
\text { dosagem }\end{array}$ & & \\
\hline
\end{tabular}

$\begin{array}{cccl}\begin{array}{c}\text { Primavera } \\ 2000\end{array} & 20 & 1 & \begin{array}{l}\text { Picnose e acidofilia citoplasmática de } \\ \text { hepatócitos periportais. }\end{array} \\ \begin{array}{c}\text { Primavera } \\ 2000\end{array} & 20 & 3 \text { a } 7 & \begin{array}{l}\text { Necrose e desorganização da arquite- } \\ \text { tura lobular. Hemorragia, basofilia do } \\ \text { citoplasma de hepatócitos mediozo- } \\ \text { nais, von Kossa positivo. }\end{array}\end{array}$

$\begin{array}{lll}\text { Verão } & 20 \quad 1 \quad \begin{array}{l}\text { Vacuolização de hepatócitos centro- } \\ \text { lobulares e acúmulo de neutrófilos } \\ \text { nos sinusóides. }\end{array}\end{array}$

\begin{tabular}{|c|c|c|c|}
\hline $\begin{array}{l}\text { Verão } \\
2001\end{array}$ & 20 & 3 & $\begin{array}{l}\text { Degeneração centrolobular, necrose } \\
\text { de hepatócitos periportais e eritró- } \\
\text { citos extravasados. Fibrose portal } \\
\text { moderada e proliferação de ductos. }\end{array}$ \\
\hline
\end{tabular}

$\begin{array}{llll}\begin{array}{l}\text { Verão } \\ 2001\end{array} & 20 & 7 & \begin{array}{l}\text { Vacuolização moderada hepatócitos } \\ \text { periportais e fibrose portal. }\end{array} \\ \begin{array}{l}\text { Verão } \\ 2001\end{array} & 30 & 1 & \begin{array}{l}\text { Vacuolização de hepatócitos centro- } \\ \text { lobulares e mediozonais. Vacuoli- } \\ \text { zação difusa. }\end{array} \\ \begin{array}{l}\text { Verão } \\ 2001\end{array} & 30 & 3 & \begin{array}{l}\text { Necrose de hepatócitos periportais e } \\ \text { hemorragia, vacuolização de hepató- } \\ \text { citos centrolobulares e mediozonais, } \\ \text { proliferação de ductos. Vacuolização } \\ \text { difusa. }\end{array}\end{array}$

Verão $\quad 30 \quad 7 \quad$ Necrose periportal, acúmulo de 2001 neutrófilos nos sinusóides, fibrose e proliferação de ductos, poucos hepatócitos com fino granulado von Kossa positivo. fases mais avançadas, os hepatócitos apresentavam contornos pouco nítidos, ruptura da membrana citoplasmática, núcleos picnóticos, vacuolizações do citoplasma e destruição de organelas. Nas localizações que se mostraram von Kossa positivas, foram observados hepatócitos degenerados ou necróticos exibindo numerosos grânulos citoplasmáticos eletrodensos com contornos irregulares, medindo $300 \mathrm{~nm}$ a $2 \mathrm{~mm}$, alguns parcial ou totalmente delimitados por membrana, com morfologia compatível com cristais de cálcio (Fig. 3). Em grandes aumentos, esses grânulos mostravam ser constituídos por cristais aciculares de 30 a 40nm (Fig. 4). Algumas células de Kupffer exibiam numerosos corpos residuais no citoplasma.

No ovino que recebeu $20 \mathrm{~g} / \mathrm{kg}$ no mês de janeiro, verificou-se hiperplasia do REL e aumento significativo dos vacúolos com bile, já nas 24 horas iniciais. Em alguns hepatócitos, havia tumefação de mitocôndrias, algumas com cavitações da matriz. Diversos hepatócitos exibiam núcleos de contornos irregulares
Hiperplasia do REL.

Hiperplasia acentuada do REL, tumefação de hepatócitos, degranulação e vesiculação do RER, dilatação de mitocôndrias. Contornos citoplasmáticos pouco nítidos, núcleos picnóticos. As áreas von Kossa positivo apresentavam hepatócitos degenerados ou necróticos com numerosos grânulos citoplas-máticos eletrodensos constituídos por cristais aciculares, alguns parcial ou totalmente delimitados por membrana. Células de Kupffer com corpos residuais citoplasmáticos.

Hiperplasia do REL e retenção biliar. Tumefação e cavitações da matriz de mitocôndrias, núcleos irregulares e cromatina condensada. Tumefação e degranulação do RER. Alterações necróticas similares às previamente descritas. Presença de fibrina em espaços de Disse dilatados. Imagens negativas de cristais.

Acentuada diminuição das cisternas do REL e dos vacúolos com bile. Hepatócitos degenerados com vacuolizações citoplasmáticas irregulares, parcialmente delimitadas por membrana e com um conteúdo vesiculoso e eletrodenso.

Diminuição das cisternas mais evidente ainda.

Hiperplasia do REL, aumento de vacúolos com bile e gotas de gordura. RER dilatado e com degranulação moderada.

Tumefação, vesiculação e degranulação do RER, vacuolizações do citoplasma, diminuição e desaparecimento do REL, tumefação e ruptura das mitocôndrias, núcleos com contornos irregulares, cromatina condensada e cariorrexia. Liberação do conteúdo citoplasmático no interstício e presença de eritrócitos extravasados nos hepatócitos. Endotélio sinusoidal dilatado, com vacuolizações citoplasmáticas, organelas escassas e mal definidas. Espaços de Disse com restos de organelas de hepatócitos necróticos, eritrócitos extravasados.

Desaparecimento dos hepatócitos necróticos e de organelas e eritrócitos do interstício. Regeneração: incremento do RER e dos ribossomos livres.

e cromatina mais condensada. Essas alterações geralmente estavam acompanhadas de tumefação e degranulação do RER e tumefação das mitocôndrias. As alterações necróticas eram similares às descritas nos ovinos que receberam a planta no mês de outubro. Foi observada a presença de fibrina em alguns espaços de Disse muito dilatados. Em algumas localizações, foram encontradas imagens negativas de cristais, geralmente, em forma de crescente medindo 3 a $6 \mathrm{~mm}$. No $3^{\circ}$ dia após a dosagem, havia acentuada diminuição das cisternas do REL e dos vacúolos com bile. Em muitos desses hepatócitos degenerados, foram vistas vacuolizações irregulares no citoplasma, parcialmente delimitadas por membrana e com um conteúdo, finamente, vesiculoso e, acentuadamente, eletrodenso (Fig. 5). No $7^{\circ} \stackrel{\text { dia, }}{ }$ acentuou-se ainda mais a diminuição das cisternas do REL, mas o número de vacúolos com bile e as dilatações das cisternas do RER permaneceram inalterados.

Nos ovinos que receberam $30 \mathrm{~g} / \mathrm{kg}$ em janeiro foi observa- 


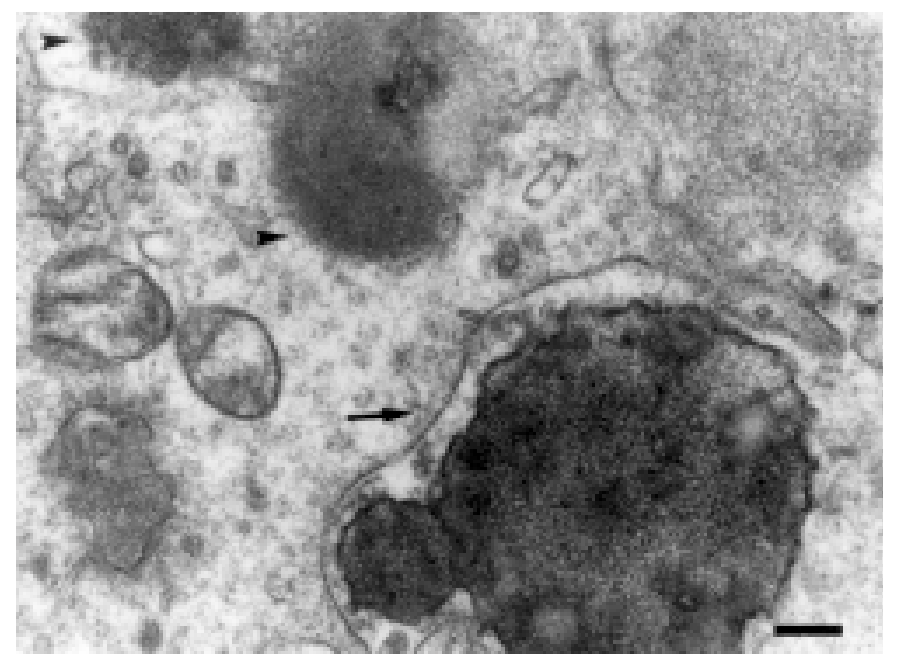

Fig. 4. Micrografia eletrônica. Fígado. Ovino. Maior aumento da Fig. 3. Os grânulos eletrodensos são constituídos por finos cristais aciculares. Dois grânulos estão livres no citoplasma (cabeça de seta) e outro está delimitado por membrana (seta). As mitocôndrias não exibem mineralização. Barra $=0,25 \mu \mathrm{m}$

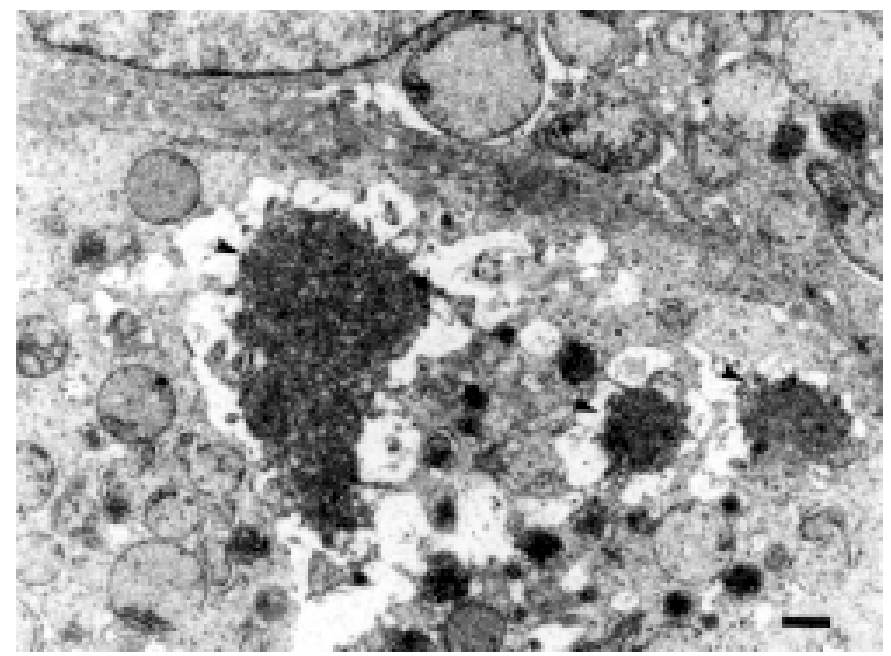

Fig. 5. Micrografia eletrônica. Fígado. Ovino. Hepatócito mostrando estruturas finamente vesiculares e eletrodensas (cabeça de seta) e interpretadas como retículo endoplasmático liso em processo de involução. Na periferia dessas estruturas observam-se espaços claros parcialmente delimitados por membrana. Barra $=0,5 \mu \mathrm{m}$.

do, nas 24 horas, moderado aumento do REL e dos vacúolos com bile, além de algumas gotas de gordura. O RER estava dilatado e com degranulação moderada. No $3^{\circ}$ dia depois da administração da planta, havia alterações degenerativonecróticas dos hepatócitos caracterizadas por tumefação, vesiculação e degranulação do RER, vacuolizações do citoplasma, diminuição ou desaparecimento do REL, tumefação e ruptura das mitocôndrias, núcleos com contornos irregulares e cromatina condensada, evoluindo, às vezes, para cariorrexia. Em muitos hepatócitos, observaram-se ruptura da membrana celular e liberação do conteúdo citoplasmático no interstício, freqüentemente, acompanhada de eritrócitos extravasados. O endotélio dos capilares sinusóides exibia acentuada dilatação com vacuolizações citoplasmáticas e organelas escassas e mal definidas, embora a membrana basal estivesse, geralmente, bem conservada. Os espaços de Disse, em muitos locais, exibiam restos de organelas de hepatócitos rompidos ou necróticos associados com eritrócitos extravasados e atrofia ou ausência de microvilosidades. No $7^{\circ}$ dia, notou-se o desaparecimento dos hepatócitos necróticos e de organelas e eritrócitos do interstício, além de evidentes características de reparação, traduzidos por um significativo incremento do RER e dos ribossomos livres. Tanto os achados microscópicos, quanto os ultra-estruturais observados nos ovinos estão apresentados, resumidamente, no Quadro 2.

\section{Bovinos}

Sinais clínicos. Nos bovinos que ingeriram 20 e $30 \mathrm{~g} / \mathrm{kg}$ de Myoporum laetum, observaram-se depressão, ausência ou diminuição dos movimentos ruminais, fezes amolecidas, mucosas avermelhadas, ranger de dentes e corrimento seroso ocular e nasal.

Achados histológicos. Os bovinos que receberam 20 e $30 \mathrm{~g} /$ $\mathrm{kg}$ apresentaram, a partir de 24 horas, hepatócitos com conteúdo citoplasmático finamente granular, PAS positivo, tornando-se mais evidente do $4^{\circ}$ ao $8^{\circ}$ dias do experimento. Os hepatócitos, predominantemente, da área periportal mostraram-se corados mais intensamente por PAS.

Achados ultra-estruturais. Os fígados dos bovinos que receberam $20 \mathrm{~g} / \mathrm{kg}$ da planta não apresentaram alterações notáveis. Entretanto, constataram-se pequenas diferenças no conteúdo de glicogênio, não só entre os diferentes hepatócitos de um mesmo lóbulo, mas também entre os diferentes dias do experimento. Um discreto aumento do REL foi verificado nos dias 1, 3 e 7 após a dosagem, havendo, entretanto, variabilidade entre os diferentes hepatócitos de um mesmo lóbulo. A distribuição do RER não estava alterada, bem como o número e a distribuição dos ribossomos livres. Foram observados alguns poucos vacúolos contendo bile. A presença e o número desses vacúolos não variaram, significativamente, entre os dias 1, 3 e 7.

Nos bovinos que receberam $30 \mathrm{~g} / \mathrm{kg}$ da planta, foi verificado aumento dos grânulos de glicogênio, em forma de roseta ou monoparticulada, freqüentemente, associados ao REL. Foi observado um discreto aumento do REL no $3^{\circ}$ dia, mas que regrediu no $7^{\circ}$ dia após receber a planta. A distribuição e o número das cisternas do RER e dos vacúolos com bile não diferiram, substancialmente, durante o experimento.

Todos os ovinos e bovinos utilizados nesse experimento ficaram totalmente recuperados após 20 a 30 dias do experimento.

\section{DISCUSSÃO}

Os sinais clínicos observados nos ovinos deste experimento foram similares aos descritos em observações anteriores (Ragonese 1956, Connor 1977, Allen et al. 1978, Hrdlicka et 
al. 1978, Raposo et al. 1998a). Em bovinos, foram mais discretos.

As lesões microscópicas observadas nos ovinos se caracterizaram, inicialmente, por vacuolização dos hepatócitos centrolobulares e evoluíam principalmente para necrose hepática periportal. Raposo et al. (1998a) observaram, principalmente, necrose hepática periportal. Em alguns casos havia, também, hemorragia e, às vezes, a área de necrose se estendia até a região mediozonal. Proliferação de ductos biliares foi, também, observada. Lesões similares foram descritas em ovinos intoxicados experimentalmente com folhas de $M$. deserti (Allen \& Seawright 1973) e folhas de M. tetrandrum administradas em três parcelas dentro de 24 horas. Porém, dose única de folhas de $M$. tetrandrum e óleos de $M$. deserti que levaram à morte dentro de 24 horas, causaram necrose centrolobular (Allen et al. 1978). Portanto, parece que a variação na localização predominante da necrose de hepatócitos está associada à distribuição e atividade das MMFO hepáticas.

A hiperplasia acentuada do retículo endoplasmático liso foi à primeira alteração ultra-estrutural encontrada nos ovinos e foi interpretada como resposta do mecanismo de detoxificação hepática. A hiperplasia do REL parece ter sido mais acentuada nos animais que receberam $20 \mathrm{~g} / \mathrm{kg}$ do que nos que receberam $30 \mathrm{~g} / \mathrm{kg}$. O REL é a organela ativa na biotransformação de drogas não-polares, através do sistema das oxidases de função mista da citocromo P-450 (Marzella \& Trump 1991). Tem sido demonstrado que diferentes rebanhos de ovinos podem apresentar diferentes níveis de atividade média de suas oxidases de função mista microssomal (MMFO), e que a atividade das enzimas sob condições de campo pode variar com a estação do ano e com a dieta (Seawright et al. 1978). Supõe-se, que as discrepâncias entre as lesões que ocorreram nos ovinos deste estudo possam estar associadas a fatores individuais dos animais, incluindo aquelas inerentes à atividade das MMFO hepáticas no momento da administração da planta tóxica.

As imagens negativas de cristais, semelhantes às observadas em casos envolvendo plantas que contém saponinas (Driemeier et al. 1998), devem ser atribuídas, provavelmente, à presença de sapogeninas no Myoporum sp. No entanto, não há relatos da presença de saponinas em Myoporum laetum. É provável ainda que a presença destes cristais, semelhantes aos encontrados em animais que ingerem Brachiaria spp (Driemeier et al. 1998), estejam relacionados com a patogenia da fotossensibilização. Os grânulos basofílicos encontrados no citoplasma dos hepatócitos degenerados e necróticos e que na ultra-estrutura eram compostos por agregados cristalinos, são sais de cálcio, o que foi confirmado pelo método de von Kossa. Essas formações cristalinas livres no citoplasma ou delimitadas por membrana, em alguns hepatócitos ainda viáveis, sugerem um processo de calcificação intracelular não associado a mitocôndrias. Desde que a manutenção da energia mitocondrial normal é essencial para manter o potencial que dirige a tomada de cálcio, os depósitos de cálcio podem teoricamente se formar em células viáveis. Outra possibilidade é a formação de depósitos de cálcio em células não-viá- veis como conseqüência do equilíbrio osmótico alterado em células necróticas. Portanto, os depósitos iniciais de cálcio podem surgir na célula, agindo como centros de nucleação que, posteriormente, recebem precipitados adicionais formando cristais de cálcio (Marzella \& Trump 1991). Notável, também foi a rápida reparação do parênquima hepático aos 8 dias, observada mesmo em animais com acentuadas alterações degenerativo-necróticas. As estruturas finamente vesiculares e acentuadamente eletrodensas observadas, foram interpretadas como agrupamentos de cisternas do REL em processo de involução, secundário à hiperplasia observada 24 horas após a dosagem com a planta.

As lesões verificadas em bovinos dosados com $20-30 \mathrm{~g} / \mathrm{kg}$ da planta foram apenas discretas sem um padrão definido de necrose, o que poderia ser atribuído a variações individuais ou à concentração do princípio tóxico da planta. Raposo et al. (1998b) observaram em um bovino que morreu após ter ingerido $40 \mathrm{~g} / \mathrm{kg}$ de $M$. laetum, necrose centrolobular hemorrágica e vacuolização do citoplasma dos hepatócitos circunjacentes. Em outros seis bovinos que receberam a mesma dose e não morreram, nas biopsias hepáticas observaram, também, principalmente necrose centrolobular, sendo às vezes, hemorrágica e, em alguns casos, estendendo-se até a área mediozonal. Descrições semelhantes foram feitas por Allen et al. (1978), em terneiros dosados com folhas M. tetrandrum ou óleos de $M$. deserti. Quando estes autores usaram pré-tratamentos com fenobarbital e óleo de Melaleuca linariifolia, que acentuam a atividade das MMFO hepáticas, observaram necrose periportal. Eles concluíram que a zona de localização da lesão na intoxicação por Myoporum estava relacionada à prévia utilização das MMFO hepáticas induzidas por compostos alimentares. Outros autores observaram em casos espontâneos necrose hemorrágica mediozonal (Odriozola et al. 1987) e periportal (Jerrett \& Chinnock 1983), e necrose periportal em estudos experimentais (Ford \& Rivera 1978, Jerrett \& Chinnock 1983). A ocorrência de intoxicação por Myoporum sp ou outras por substâncias hepatotóxicas está na dependência de sua metabolização a metabólitos intermediários pelo fígado os quais são hepatotóxicos. A biotransformação destes tóxicos é feita através das MMFO hepáticas, as quais ocorrem em maior concentração na zona centrolobular, em concentração intermediária na mediozonal e em menor concentração na região periportal (Kelly 1993).

Nesse trabalho observou-se ainda que os bovinos demonstraram menor sensibilidade aos efeitos de Myoporum laetum. Esse fato provavelmente está associado a uma menor atividade das enzimas microssomais hepáticas nesta espécie o que já havia sido anteriormente observado (Allen et al. 1978, Raposo et al. 1998b).

Agradecimentos.- Os autores agradecem ao Programa de Núcleos de Excelência (PRONEX) pelo suporte financeiro. Aos laboratoristas Simone Silveira da Silva (Microscopia Eletrônica) e João Francisco Nunes (Histopatologia) do Departamento de Patologia Animal (FV-UFPel).

\section{REFERENNCIAS}

Allen J.G. \& Seawright A.A. 1973. The effect of prior treatment with phenobarbitone, dicophane (DDT) and ß-diethylaminoethylphenylpropyl 
acetate (SKF $525 \mathrm{~A}$ ) on experimental intoxication of sheep with the plant Myoporum deserti. Cunn. Res. Vet. Sci. 15:169-179.

Allen J.G., Seawright A.A. \& Hrdlicka J. 1978. The toxicity of Myoporum tetrandrum (Boobialla) and myoporaceous furanoid essential oils for ruminants. Aust. Vet. J. 54:287-292.

Braga M. B., Castilhos L.M.L. \& Santos M.N. 1985. Biópsia hepática em bovinos: proposta de nova técnica. Revta Centro Ciênc. Rurais, Santa Maria, 15(1):79-88.

Connor H.E. 1977. The Poisonous Plants in New Zealand. Keating, Goverment Printer, Wellington, New Zealand, p. 128-131.

Driemeier D., Barros S.S., Peixoto P.V., Tokarnia C.H., Döbereiner J. \& Brito M.F. 1998. Estudos histológico, histoquímico e ultra-estrutural de fígados e linfonodos de bovinos com presença de macrófagos espumosos ("foam cells"). Pesq. Vet. Bras. 18(1):29-34

Ford E.J.H. \& Rivera R. 1978. The modification of the dehydromyodesmoneinduced hepatic lesion in cattle by microssomal drug metabolizing enzymes. J. Comp. Path. 88:365-380.

Hrdlicka J., Seawright A.A., Allen J.G. \& Hastie J. 1978. The toxicity of Myomontanone, a lung-damaging furanosesquiterpene from Myoporum montanum, p. 465-462. In: Keeler R.F., Van Kampen K.R. \& James L.F. (ed.) Effects of Poisonous Plants on Livestock. Academic Press, New York.

Hurst E. 1942. Poison Plants of New South Wales. Poison Plants Commitee, New South Wales, Sydney, p. 383-391.

Jerrett I.V. \& Chinnock R.J. 1983. Outbreaks of photosensitization and deaths in cattle due to Myoporum af. insulare. R. Br. toxicity. Aust. Vet. J. 60:183-186.

Kelly W.R. 1993. Liver and biliary system, p. 382-388. In: Jubb K.V.F., Kennedy P.C. \& Palmer N. (ed) Pathology of Domestic Animals. Vol. 2. ${ }^{\text {th }}$ ed. Academic Press, San Diego, California.
Marzella L. \& Trump B.J. 1991. Pathology of the liver: functional and structural alterations of hepatocyte organelles induced by cell injury, p. 93-138.. In: Meeks R.G., Harrison S.D. \& Bull R.J. (ed.) Hepatotoxicology. CRC Press, Boca Raton, Florida.

Méndez M.C. 1993. Intoxicação por Myoporum spp., p. 79-84. In: RietCorrea F., Méndez M.C. \& Schild A.L.(ed.) Intoxicações por Plantas e Micotoxicoses em Animais Domésticos. Editorial Agropecuaria Hemisferio Sur, Uruguai.

Odriozola E.R., Tapia M.O., López T.A., Casaro A.P. \& Calandra W. 1987. Intoxicación natural de bovinos con transparente (Myoporum laetum Forst.). Revta Med. Vet., Buenos Aires, 68 (4):230-232.

Ragonese A.E. 1955. Plantas Tóxicas para el Ganado. Revta Fac. Agronomia La Plata 31(2):279-281.

Raposo J.B., Méndez M.C., Riet-Correa F. \& Andrade G.B. 1998a. Experimental intoxication by Myoporum laetum in sheep. Vet. Human Toxicol. 40 (3):132135.

Raposo J.B., Méndez M.C., Andrade G.B \& Riet-Correa F. 1998b. Experimental intoxication by Myoporum laetum in cattle. Vet. Human Toxicol. 40 (5):275277.

Seawright A.A. 1968. Pattern of liver caused by ngaione in the rat. Aust. Vet. J. 44:426.

Seawright A.A. \& O'Donahoo M. 1973. Light- and electron-microscope observations of the liver of the mouse after a single oral dose of ngaione. J. Path. 106:251-259.

Seawright A.A., Lee J.S., Allen J.G. \& Hrdlicka J. 1978. Toxicity of Myoporum spp. and their furanosesquiterpenoid essential oils., p. 241-250. In: Keeler R.F., Van Kampen K.R. \& James L.F. (ed.) Effects of Poisonous Plants on Livestock. Academic Press, New York. 